\title{
THE DYNAMIC INTERRELATION OF VN-INDEX AND MAJOR WORLD STOCK MARKETS: BAYESIAN DCC-GARCH APPROACH
}

\author{
Dong Manh Cuong*, Tran Minh Chau
}

$T N U$ - International School

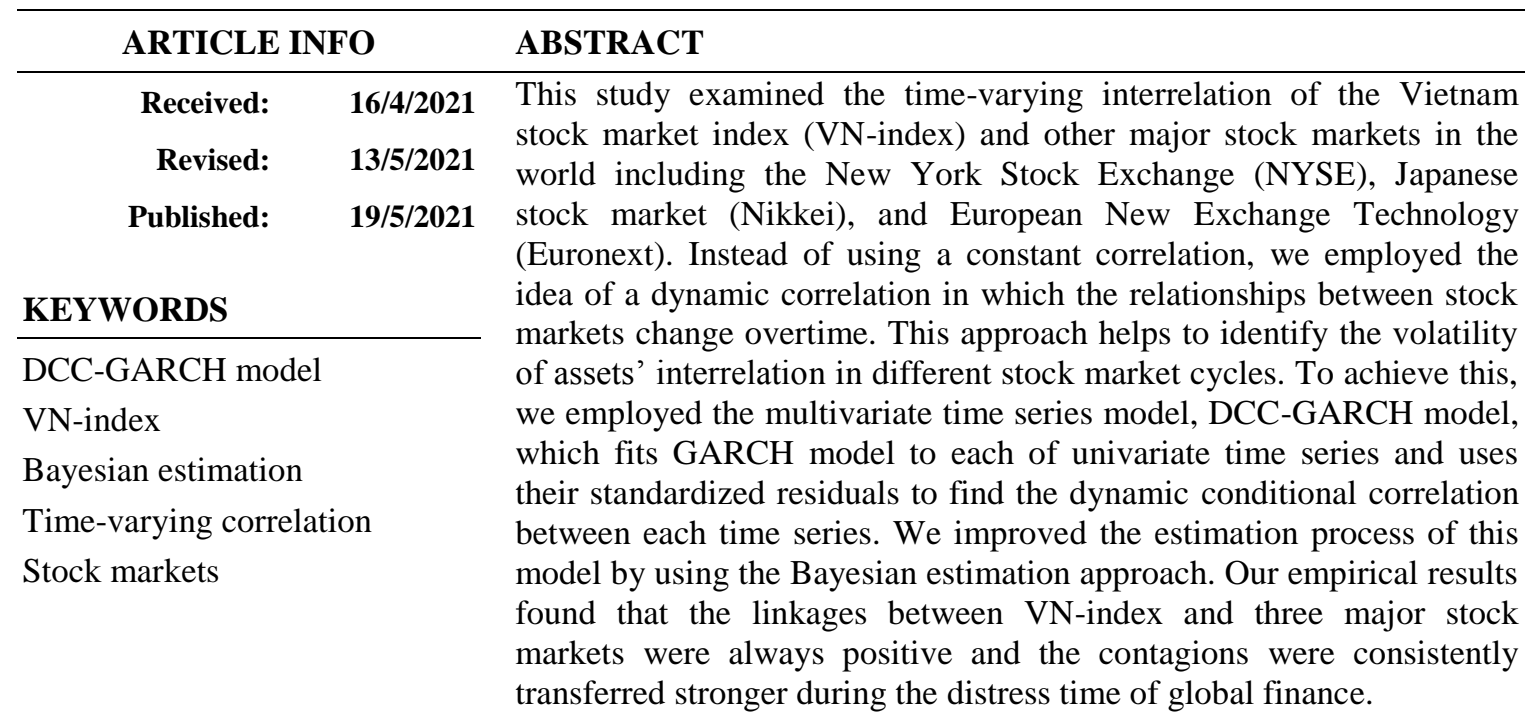

\section{TÌM HIỂU MỐI TƯƠNG QUAN ĐộNG GIŨ̃A VN-INDEX VÀ CÁC THI! TRƯờnG CHÚNG KHOÁN LỚN TRÊN THẾ GIỚI THÔNG QUA MÔ HİNH BAYESIAN DCC-GARCH}

Đồng Mạnh Cường*, Trần Minh Châu

Khoa Quốc tế - ĐH Thái Nguyên

\begin{tabular}{|c|c|c|}
\hline THÔNG TIN BÀ & I BÁO & TÓM TẮT \\
\hline Ngày nhận bài: & $16 / 4 / 2021$ & Nghiên cứu này xem xét mối tương quan thay đổi theo thời gian của \\
\hline Ngày hoàn thiện: & $13 / 5 / 2021$ & $\begin{array}{l}\text { chỉ sô thị trường chứng khoán Việt } \mathrm{Nam} \text { (VN-index) với các thị trường } \\
\text { chứng khoán lớn trên thế giới bao gồm chỉ số chứng khoán New York }\end{array}$ \\
\hline Ngày đăng: & $19 / 5 / 2021$ & (NYSE), thị trường chứng khoán Nhật Bản (Nikkei) và chỉ số chứng \\
\hline & & khoán Châu Âu (Euronext). Bài báo sử dụng ý tưởng về mối tương \\
\hline \multicolumn{2}{|l|}{ TÙ' KHÓA } & quan động trong đó mối quan hệ giữa các thị trường chứng khoán thay \\
\hline \multicolumn{2}{|c|}{ Mô hình DCC-GARCH } & $\begin{array}{l}\text { đôi theo thời gian. Cách tiêp cận này giúp xác định sự biên động của } \\
\text { mối tương quan giữa các tài sản trong các chu kỳ thị trường chứng }\end{array}$ \\
\hline \multicolumn{2}{|l|}{ VN-index } & khoán khác nhau. Để đạt được điều này, chúng tôi sử dụng mô hình \\
\hline \multicolumn{2}{|l|}{ Ước lượng Bayesian } & chuỗi thời gian đa biến (DCC-GARCH), trong đó mô hình GARCH \\
\hline \multirow{2}{*}{\multicolumn{2}{|c|}{ Tương quan động }} & được sử dụng với từng chuỗi thời gian đơn biến và phần dư chuẩn hóa \\
\hline & & được sử dụng để tìm mối tương quan điều kiện động giữa từng chuỗi \\
\hline \multicolumn{2}{|c|}{ Thị trường chứng khoán } & $\begin{array}{l}\text { thời gian. Chúng tôi cải thiện quy trình ước lượng của mô hình này } \\
\text { bằng cách sứ dụng phương pháp ước lượng Bayes. Kết quả cho thấy } \\
\text { mối tương quan giữa VN-index và ba thị trường chứng khoán lớn luôn } \\
\text { dương và các mối liên hệ được chuyền giao mạnh mẽ hơn trong thời } \\
\text { kỳ khó khăn của tài chính toàn cầu. }\end{array}$ \\
\hline
\end{tabular}

DOI: https://doi.org/10.34238/tnu-jst.4365

\begin{tabular}{lll}
${ }^{*}$ Corresponding author. Email: cuongdm@tnu.edu.vn & \\
\hline http://jst.tnu.edu.vn & 30 & Email: jst@tnu.edu.vn
\end{tabular}




\section{Introduction}

The connection of major world stock markets is undeniable, and it is proved by many studies [1]. The main reasons to identify the linkages between stock markets are (i) portfolio diversification, (ii) stock market efficiency, (iii) financial stability, and (iv) monetary policy [2]. For those important reasons, this paper studies the time-varying linkage between the Vietnam stock market index (VN-index) and three main stock markets in three continents: New York Stock Exchange (NYSE) in America, Japanese stock market (Nikkei) in Asia, and European New Exchange Technology (Euronext) in Euro.

In finding the contagion effect of foreign stock markets on Vietnam stock market, Nguyen et al. [3] employs Chi-plots, Kendall (K)-plots and three different copula functions to empirically examine the tail dependence between the US stock market and stock markets in Vietnam. The result show that there exists stronger left tail dependence between the US and Vietnam stock markets. Vo and Ellis [4] investigates the interdependence between the Vietnamese stock market and other influential equity markets and finds correlation, return spillover and volatility linkage between Vietnamese stock market with other leading equity markets of the US, Hong Kong and Japan.

One drawback of previous related papers is that most of them examine a constant correlation between stock market. However, the relationship between assets usually changes in different market cycle. This problem raises a necessity of studying a dynamic correlation between stock market [5]. To overcome this issue, we follow the dynamic conditional correlation (DCC)GARCH model of [6], which allows the correlation matrix to depend on the time. The use of this approach has become popular recently, with applications in many fields, especially in business and finance [7] - [9].

For the estimation of this model, we employ the Bayesian estimation approach which can facilitate representing and taking fuller account of the uncertainties related to models and parameter values [10]. Using the dataset from July 2000 to March 2021, we find out that the linkages between $\mathrm{VN}$-index and three major stock markets are always positive, and the contagions are usually transferred stronger during the distress time of global finance. More specifically, during the global finance crisis in 2008-2009 and the Covid pandemic starting from 2019, the conditional dynamic correlation between VN-index and other stock markets raises dramatically.

The rest of the paper is as follows. Section 2 introduces the DCC-GARCH model, the Bayesian estimation method, and the dataset used in this study. Section 3 reports estimated results and discussion. Section 4 remarks conclusions.

\section{Model and data descriptions}

\subsection{DCC-GARCH model}

We consider a multivariate time series $\mathbf{Y}_{t}=\left(y_{1, t}, y_{2, t}, \mathrm{~K}, y_{k, t}\right)^{\prime}$ with a form:

$$
\mathbf{Y}_{t}=\mathbf{H}_{t}^{1 / 2} \boldsymbol{\varepsilon}_{t},
$$

where $\mathbf{H}_{t}^{1 / 2}$ is a positive definite matrix such that $\mathbf{H}_{t}$ is the conditional variance of $\mathbf{Y}_{t}$. The error vectors $\left(\varepsilon_{1}, \varepsilon_{2}, \mathrm{~K}, \varepsilon_{k}\right)$ are assumed to be i.i.d. Following [5] and [6], we allow the conditional covariances are proportional to the product of the corresponding conditional standard deviations and the conditional correlation matrix is time-dependent. Specifically,

$$
\mathbf{H}_{t}=\mathbf{A}_{t} \mathbf{P}_{t} \mathbf{A}_{t} \text {, }
$$


where $\mathbf{A}_{t}=\operatorname{diag}\left(h_{11, t}^{1 / 2}, \mathrm{~K}, h_{k k, t}^{1 / 2}\right), \mathbf{P}_{t}$ is a symmetric positive definite matrix which elements are time-varying conditional correlations $\rho_{i j}(i, j=1, \mathrm{~K}, k)$ and $\rho_{i j}=1$ when $i=j$.

For each conditional variance, we specify a $\operatorname{GARCH}(1,1)$ model as:

$$
h_{i i, t}=\phi_{i}+\alpha_{i} y_{i, t-1}^{2}+\beta_{i} h_{i i, t-1},
$$

where the coefficients are restricted by conditions: $\phi_{i}>0, \alpha_{i} \geq 0, \beta_{i} \geq 0$, and $\alpha_{i}+\beta_{i}<0$.

For the dynamic correlation matrix $\mathbf{P}_{t}$, we follow [6] to set:

$$
\mathbf{P}_{t}=\operatorname{diag}\left(\mathbf{Q}_{t}\right)^{-1 / 2} \mathbf{Q}_{t} \operatorname{diag}\left(\mathbf{Q}_{t}\right)^{-1 / 2},
$$

where $\mathbf{Q}_{t}$ is a $k \times k$ symmetric positive-definite matrix which elements are $q_{i j, t}(i, j=1, \mathrm{~K}, k)$. The matrix $\mathbf{Q}_{t}$ is defined by a GARCH-type equation:

$$
\mathbf{Q}_{t}=\left(1-\theta_{1}-\theta_{2}\right) \boldsymbol{\Gamma}+\theta_{1} \boldsymbol{\eta}_{t-1} \boldsymbol{\eta}_{t-1}^{\prime}+\theta_{2} \mathbf{Q}_{t-1} .
$$

In the above equation, $\boldsymbol{\eta}_{t}$ the standardized returns and $\boldsymbol{\Gamma}$ is the unconditional covariance matrix of $\boldsymbol{\eta}_{t}$. The coefficients in Equation (4) follow restrictions such that: $\theta_{1}>0, \theta_{2}>0$ and $\theta_{1}+\theta_{2}<1$.

\subsection{Bayesian estimation}

In this study, we employed the Bayesian approach to estimate the DCC-GARCH model. Comparing to classical methods (maximum likelihood or least squares), the Bayesian estimation approach can facilitate representing and taking fuller account of the uncertainties related to models and parameter values. The Bayesian method has the ability to incorporate prior information, i.e. it can take into account historical data sets or canvass expert knowledge to determine what is known about the parameters.

Since most financial data usually has fat-tail unconditional distribution, the error distribution in Model (1) should not be assumed to be a normal distribution. Instead, we followed [11] to use the multivariate Student-t distribution for the estimation of our model. We describe the density function of the multivariate Student-t distribution applying standardized error $\boldsymbol{\varepsilon}_{t}$ as follow:

$$
p\left(\boldsymbol{\varepsilon}_{t}\right)=\frac{\Upsilon\left(\frac{v+k}{2}\right)}{\Upsilon\left(\frac{v}{2}\right)[\pi(v-2)]^{k / 2}}\left[1+\frac{\boldsymbol{\varepsilon}_{t}^{\prime} \boldsymbol{\varepsilon}_{t}}{v-2}\right]^{-\frac{v+k}{2}},
$$

where $v$ is the degree of freedom (we assume $v>2$ to make sure that the conditional variance matrix $\mathbf{H}_{t}$ is interpretable) and $\Upsilon(\cdot)$ is the Gamma function.

Let $\Theta=\left(\phi_{1}, \alpha_{1}, \beta_{1}, \mathrm{~K}, \phi_{k}, \alpha_{k}, \beta_{k}, \theta_{1}, \theta_{2}, v\right)^{\prime}$ be the vector of all unknown parameters of the DCC-GARCH model. We illustrate the conditional likelihood function of Model (1) as follow:

$$
L(\boldsymbol{\Theta})=\prod_{t=1}^{n}\left[\prod_{i=1}^{k} h_{i i, t}^{-1 / 2}\right]\left|\mathbf{P}_{t}\right|^{-1 / 2} p_{\varepsilon}\left(\left(\mathbf{A}_{t} \mathbf{P}_{t} \mathbf{A}_{t}\right)^{-1 / 2} \mathbf{Y}_{t}\right),
$$

where $p_{\varepsilon}$ is the joint density function of $\boldsymbol{\varepsilon}_{t}$.

In Bayesian estimation, one of the most important tasks is to specify the prior distributions of all parameters. Then, using Bayes Theorem, the joint posterior density is proportional to the 
product of the likelihood function (6) by the joint prior density. For the parameter vector $\boldsymbol{\Theta}$, we follow to choose prior distributions as follow:

- $\phi_{i}: N\left(\mu_{\phi_{i}}, \sigma_{\phi_{i}}^{2}\right) I_{\left(\phi_{i}>0\right)}$,

- $\alpha_{i}: N\left(\mu_{\alpha_{i}}, \sigma_{\alpha_{i}}^{2}\right) I_{\left(0<\alpha_{i}<1\right)}$,

- $\beta_{i}: N\left(\mu_{\beta_{i}}, \sigma_{\beta_{i}}^{2}\right) I_{\left(0<\beta_{i}<1\right)}$,

- $\theta_{1}: N\left(\mu_{\theta_{1}}, \sigma_{\theta_{1}}^{2}\right) I_{\left(0<\theta_{1}<1\right)}$,

- $\theta_{2}: N\left(\mu_{\theta_{2}}, \sigma_{\theta_{2}}^{2}\right) I_{\left(0<\theta_{2}<1\right)}$,

- $v: N\left(\mu_{v}, \sigma_{v}^{2}\right) I_{(v>2)}$.

For the above prior distributions, we kept the values of the hyperparameters constant as follows: $\mu_{\phi_{i}}=\mu_{\alpha_{i}}=\mu_{\beta_{i}}=\mu_{\theta_{1}}=\mu_{\theta_{2}}=\mu_{v}=0$ and $\sigma_{\varphi_{i}}^{2}=\sigma_{\alpha_{i}}^{2}=\sigma_{\beta_{i}}^{2}=\sigma_{\theta_{1}}^{2}=\sigma_{\theta_{2}}^{2}=\sigma_{v}^{2}=100$. All of our conditional posterior distributions are non-standard forms. Therefore, we employed the Markov chain Monte-Carlo (MCMC) method and sample parameters in their respective order, from their conditional posterior distribution, to make inferences for the parameters. We performed 10,000 MCMC iterations and discard the first 3,000 iterations as a burn-in sampler. For the MCMC process checking, we examined the trace and autocorrelation function (ACF) plots after the burn-in MCMC sampling to confirm convergence and uncorrelation.

\subsection{Data description}

Our dataset contains four stock market indices including the Vietnam stock market index (VN-index), New York Stock Exchange (NYSE), Japanese stock market (Nikke), and European New Exchange Technology (Euronext). The dataset covers a period from July 2000 to March 2021. Since the original stock price data is not stationary and not adequate to fit the DCCGARCH model, we calculate the returns, $R_{t}$, of each stock index using an equation: $R_{t}=\left(\log \left(P_{t}\right)-\log \left(P_{t-1}\right)\right) \times 100$ where $P_{t}$ is the close index at day $t$. Table 1 summarizes the descriptive statistics of four stock indices' returns. Although VN-index is the smallest market (min and max returns are smallest among 4 markets), it has the highest average returns compared to other stock markets. To check for stationary, we employ the Augmented Dickey-Fuller (ADF) test and we report its p-values results in the last column of Table 1. The ADF test shows that all four returns series are stationary and they are adequate for the DCC-GARCH model.

Table 1. Descriptive statistics for returns of 4 stock indices

\begin{tabular}{lccccc}
\hline Variables & Min & Max & Average & $\begin{array}{c}\text { Standard } \\
\text { deviation }\end{array}$ & $\begin{array}{c}\text { ADF test } \\
\text { p-value }\end{array}$ \\
\hline VN-index & -3.32 & 3.36 & 0.02 & 0.65 & 0.00 \\
NYSE & -5.47 & 4.27 & 0.00 & 0.55 & 0.00 \\
Nikkei & -5.26 & 5.75 & 0.01 & 0.65 & 0.00 \\
Euronext & -5.54 & 3.68 & 0.00 & 0.57 & 0.00 \\
\hline
\end{tabular}

Figures 1 illustrates the time series plots of four stock indices' returns. It is easy to observe from Figure 1 that the patterns of all four indices are quite similar and all four markets' returns are stationary. 

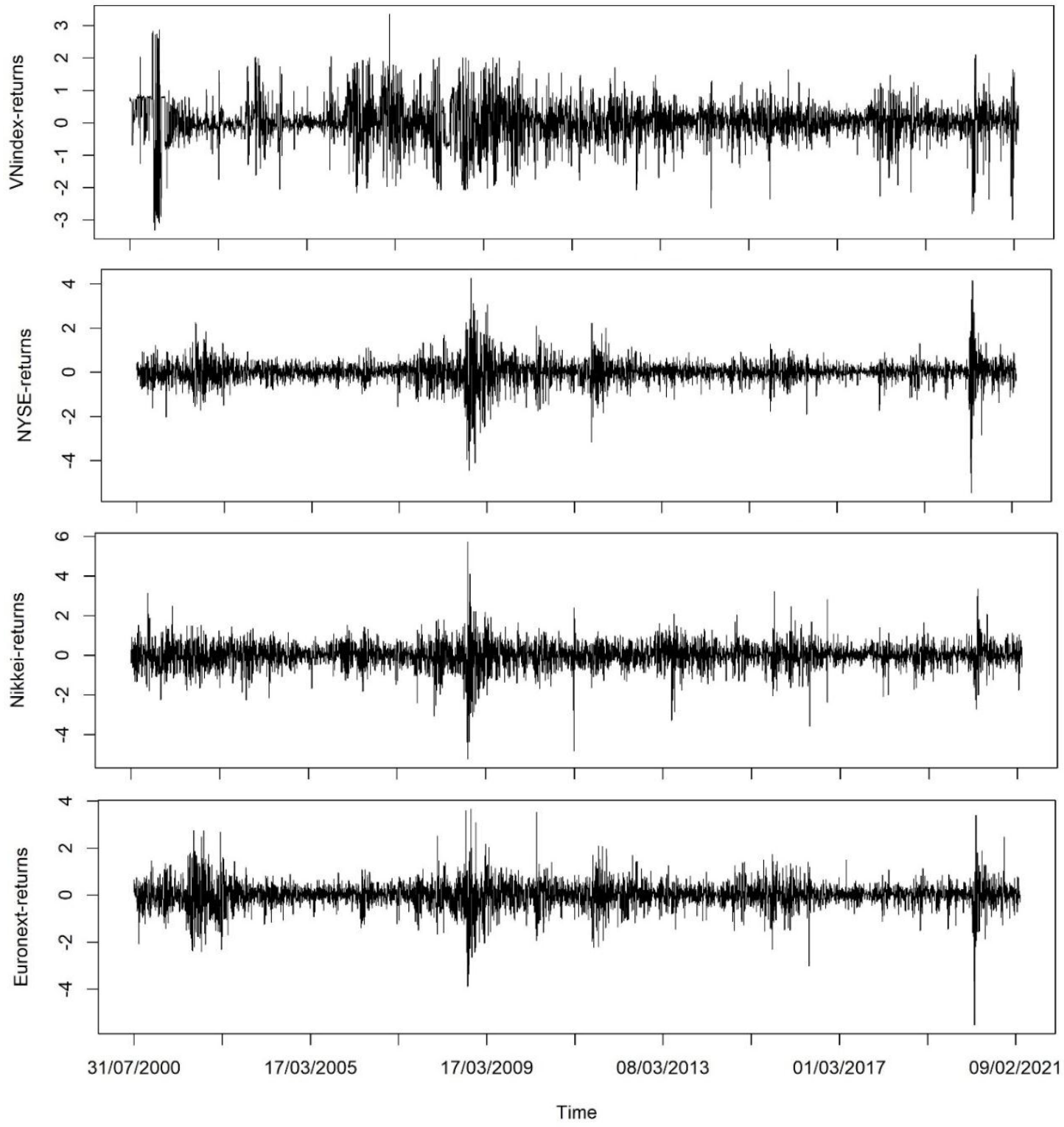

Figure 1. Plots of returns for 4 stock markets

\section{Results and discussion}

Table 2 reported the estimated coefficients of the DCC-GARCH model using the Bayesian estimation approach. For each parameter, we reported the mean, median, standard deviation, and the 95\% credible interval $\left(\mathrm{P}_{2.5}\right.$ and $\mathrm{P}_{97.5}$ indicates the interval from $2.5 \%$ to $\left.97.5 \%\right)$. If the $95 \%$ credible interval of one parameter did not include value zero, i.e. all values from $P_{2.5}$ to $P_{97.5}$ had the same sign (positive or negative), we considered that parameter significant. Conversely, if the 95\% credible interval of one parameter included value zero, that parameter would be considered insignificant. The results showed that GARCH-part coefficients $\left(\phi_{i}, \alpha_{i}\right.$, and $\left.\beta_{i}\right)$ in Equation (3) of all four series were significantly positive. It indicated that the returns and lag-volatilities had a positive impact on the conditional volatility in all 4 stock markets. Besides, the DCC-part coefficients $\left(\theta_{i}\right)$ showed a persistency when $\theta_{1}+\theta_{2}>0.9$. 
Table 2. Bayesian estimation of DCC-GARCH model

\begin{tabular}{lccccc}
\hline Parameters & Mean & Median & Standard deviation & $\mathbf{P}_{2.5}$ & $\mathbf{P}_{97.5}$ \\
\hline$\phi_{1}$ & 0.01 & 0.01 & 0.00 & 0.01 & 0.01 \\
$\alpha_{1}$ & 0.22 & 0.22 & 0.02 & 0.19 & 0.25 \\
$\beta_{1}$ & 0.77 & 0.77 & 0.02 & 0.73 & 0.80 \\
$\phi_{2}$ & 0.00 & 0.00 & 0.00 & 0.00 & 0.01 \\
$\alpha_{2}$ & 0.11 & 0.11 & 0.01 & 0.09 & 0.12 \\
$\beta_{2}$ & 0.88 & 0.88 & 0.01 & 0.86 & 0.90 \\
$\phi_{3}$ & 0.01 & 0.01 & 0.00 & 0.01 & 0.01 \\
$\alpha_{3}$ & 0.10 & 0.10 & 0.01 & 0.08 & 0.12 \\
$\beta_{3}$ & 0.88 & 0.88 & 0.01 & 0.85 & 0.90 \\
$\phi_{4}$ & 0.01 & 0.01 & 0.00 & 0.00 & 0.01 \\
$\alpha_{4}$ & 0.09 & 0.09 & 0.01 & 0.08 & 0.11 \\
$\beta_{4}$ & 0.89 & 0.89 & 0.01 & 0.87 & 0.91 \\
$\theta_{1}$ & 0.01 & 0.01 & 0.00 & 0.00 & 0.02 \\
$\theta_{2}$ & 0.92 & 0.94 & 0.05 & 0.78 & 0.98 \\
$v$ & 7.03 & 7.03 & 0.23 & 6.61 & 7.50 \\
\hline $\begin{array}{l}\text { Model diagnostic criteria } \\
\text { EAIC }\end{array}$ & 21346.06 & & & & \\
EBIC & 21467.98 & & & & \\
DIC & 21325.66 & & & & \\
\hline
\end{tabular}

Figure 3 illustrated the time-varying co-volatilities of $\mathrm{VN}$-index and the other three stock markets. Our main focus in this paper is about VN-index, thus we did not consider the covolatilities of other pairs. We observed that the correlations between $\mathrm{VN}$-index and other stock markets were consistently positive regardless of the state of the world economy. However, one interesting point is that these co-volatilities increased suddenly during the difficult times of the world economy, i.e. global financial crisis in 2008 or the Covid-19 during 2020. It proved that the stock market of Vietnam was sensitive to the change of major world stock markets during the downward of the world economy.

Figure 4 plotted the conditional volatilities of four stock markets estimated by the DCCGARCH model. The results proved that our model could find the volatilities of stock markets very well when it was able to catch all the sudden changes in returns of stock markets. To check for the convergence and uncorrelation of the MCMC series, we examined the MCMC trace plots and ACF plots of each parameter (results provided upon request). From the diagnostic check, it was confirmed that there was no problem with our MCMC process. 


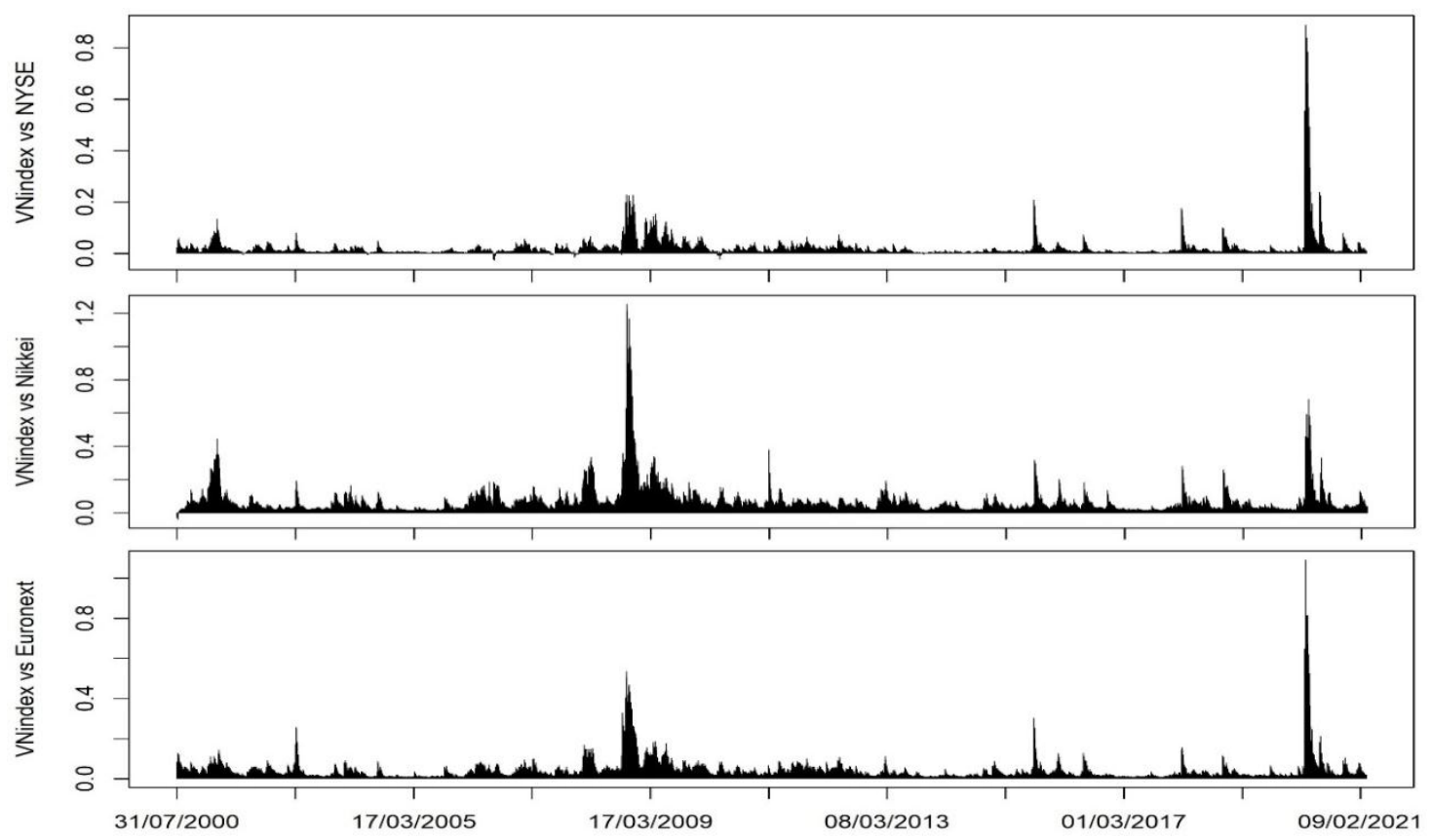

Figure 3. The time-varying co-volatilities of $V N$-index versus three major stock markets
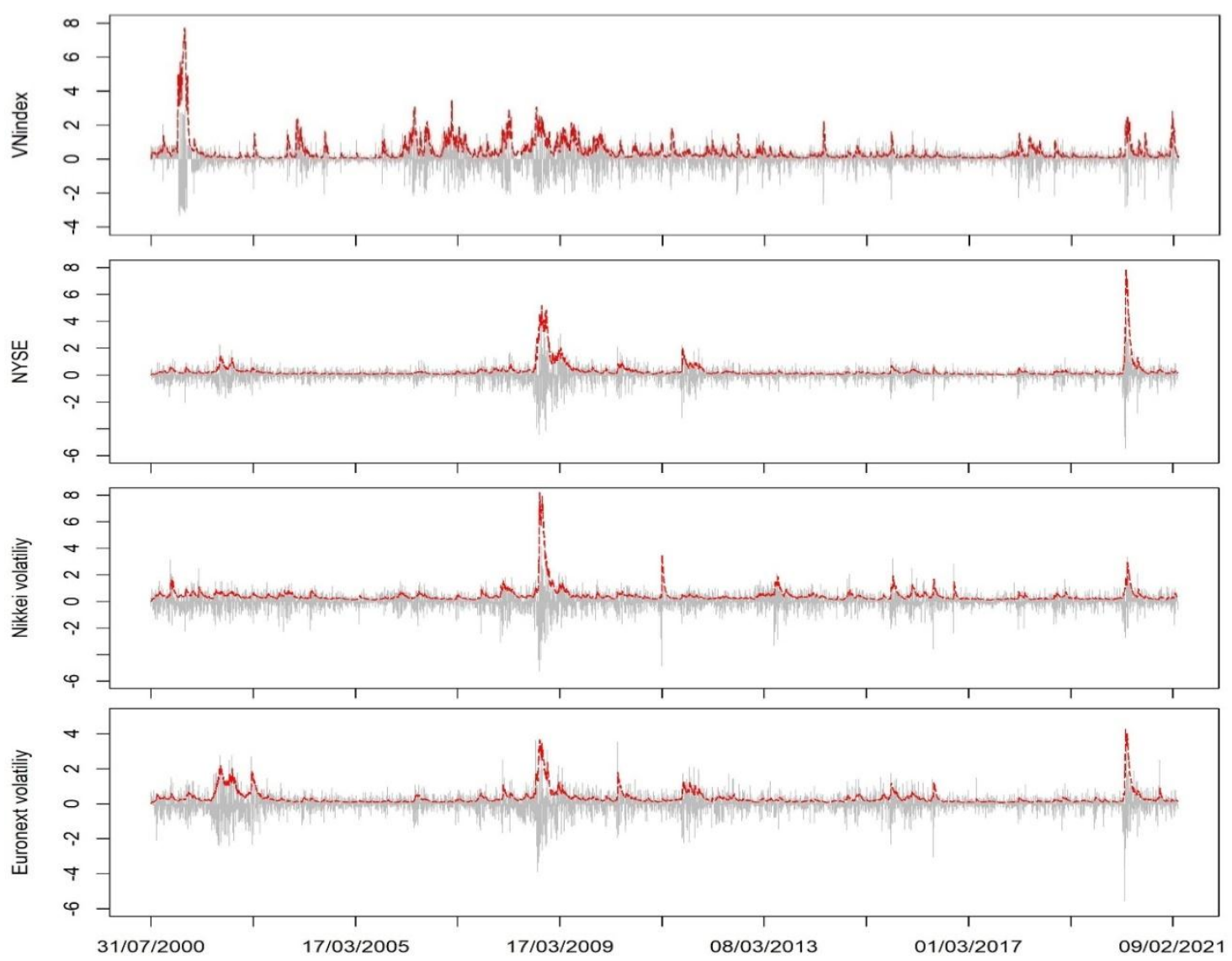

Figure 4. Conditional volatilities of 4 stock markets' returns based on DCC-GARCH model 


\section{Conclusion}

This paper studied the dynamic linkages of the Vietnam stock market index and other major stock markets in the world including NYSE, Nikkei, and Euronext. Our dataset covers a period from July 2000 to March 2021. The advantage of our dataset is that it can cover several distress times of the world economy including the global financial crisis in 2008 and the Covid-19 crisis in 2020. Using the DCC-GARCH model with Bayesian estimation, we found that the interrelation between $\mathrm{VN}$-index and three major stock markets were always positive and the contagions were usually transferred stronger during the distress time of global finance.

\section{REFERENCES}

[1] G. Cifarelli and G. Paladino, "Volatility linkages across three major equity markets: A financial arbitrage approach," Journal of International Money and Finance, vol. 24, pp. 413-439, 2005.

[2] Z. Chinzara and M. J. Aziakpono, "Dynamic returns linkages and volatility transmission between south African and world major stock markets," Studies in Economics and Econometrics, vol. 33, pp. 69-94, 2009.

[3] C. Nguyen, M. I. Bhatti, and D. Henry, "Are Vietnam and Chinese stock markets out of the US contagion effect in extreme events?" Physica A: Statistical Mechanics and its Applications, vol. 480, pp. 10-21, 2017.

[4] X. V. Vo and C. Ellis, "International financial integration: Stock return linkages and volatility transmission between Vietnam and advanced countries," Emerging Markets Review, vol. 36, pp. 19-27, 2018.

[5] Y. K. Tse and A. K. C. Tsui, "A multivariate GARCH model with time-varying correlations," Journal of Business and Economic Statistics, vol. 20, pp. 351-362, 2002.

[6] R. F. Engle, "Dynamic conditional correlation - a simple class of multivariate GARCH models," Journal of Business and Economic Statistics, vol. 20, pp. 339-350, 2002.

[7] S. Celik, "The more contagion effect on emerging markets: The evidence of DCC-GARCH model," Economic Modelling, vol. 29, pp. 1946-1959, 2012.

[8] P. M. Jones and E. Olson, "The time-varying correlation between uncertainty, output, and inflation: Evidence from a DCC-GARCH model," Economics Letters, vol. 118, pp. 33-37, 2013.

[9] J. H. Cho, and A. M. Parhizgari, "East Asian Financial Contagion under DCC-Garch," International Journal of Banking and Finance, vol. 6, pp. 17-30, 2009.

[10] C. W. S. Chen, R. Gerlach, and E. M. H. Lin, "Bayesian estimation of smoothly mixing time-varying parameter GARCH models," Computational Statistics and Data Analysis, vol. 76, pp. 194-209, 2014.

[11] J. A. Fioruci, R. S. Ehlers, and M. G. A. Filho, "Bayesian multivariate GARCH models with dynamic correlations and asymmetric error distributions," Journal of Applied Statistics, vol. 41, pp. 320-331, 2014. 